\title{
Low Achieving Students' Realization of the Notion of Mathematical Equality with an Interactive Technological Artifacts
}

\author{
Osama Swidan ${ }^{1}$, Wajeeh M. Daher ${ }^{2,3^{*}}$ \\ ${ }^{1}$ Ben-Gurion University of the Negev, P.O.B. 653, Be'er-Sheva, 8410501, ISRAEL \\ 2 Al-Qasemi Academic College of Education, P.O.B. 124, Baqa-El-Gharbia, 30100, ISRAEL \\ ${ }^{3}$ An-Najah National University, P.O.B 7, Nablus, PALESTINE
}

Received 9 June 2018 - Revised 27 September 2018 - Accepted 4 December 2018

\begin{abstract}
In this study we analyzed the discursive actions employed by low-achieving students when they used an interactive technological artifact that simulates a two-pan balance scale to learn about mathematical equality. The study was guided by the commognition framework. Three pairs of low-achieving 16-year-old students participated in this study, in which they were asked to use the artifact to compare mathematical expressions. The results indicate that the commognitive processes exploited by students as they learned the mathematical equality-inequality were reflected in the evolution of their discourse. This evolution was present in the sequence of routines, with which the students were engaged. This routine evolution advanced from everyday discourse into mathematical discourse. The routines' evolution was guided by the teacher, and therefore, we conclude that the combination of the potentials of the artifact together with the teacher's actions helped students understand the mathematical equality-inequality.
\end{abstract}

Keywords: commognition, discourse, equality, low-achieving students, technological tools

\section{INTRODUCTION}

While both the learning processes of low-achieving students and the teaching methods implemented to school them have attracted the academic attention of educators for decades, these processes should be understood through a different lens. Indeed, to understand the teaching/learning dynamics that typify the educational experiences of low-achieving students, previous research has relied heavily on cognitive theories, which conceptualize thinking as a mental activity, and as such, work in the field focused mainly on the set of mental procedural mechanisms possessed by the student (Radford, 2008). Sociocultural theories of learning, in contrast, consider thinking to be a mode of reflective, socially and culturally mediated praxis (Radford, 2008). In so doing, these theories represent a new opportunity to understand how the learning processes of low-achieving students are affected by this praxis. The need to understand the impact of sociocultural elements on thinking has long been emphasized by researchers such as Geertz (1973), who argues that students' thinking is "thoroughly dependent upon cultural resources for its very operation; and those resources are, consequently, not adjuncts to, but constituents of, mental activity" (p. 76). Indeed, one of the bases of the commognitive approach to learning comprises the need to understand the social interactions integral to students' learning. Likewise, Sfard (2008) conceives of human thinking as having a collective characteristic, namely, interpersonal communication. In line with Vygotsky, she argues that the individual's learning process "refers to culturally produced and constantly modified outcomes of collective human efforts" (p. 77).

To promote better learning of mathematics among low-achieving students, one recommendation is to design the classroom environment to be conducive to learning (Leone, Wilson, \& Mulcahy, 2010). This can be done by, among other things, giving students real-context tasks to solve and by providing them with the dynamic tools needed for task completion (National Council of Teachers of Mathematics, 2000) while simultaneously maintaining

(C) 2019 by the authors; licensee Modestum Ltd., UK. This article is an open access article distributed under the terms and conditions of the Creative Commons Attribution License (http://creativecommons.org/licenses/by/4.0/).

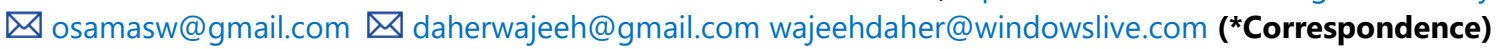




\section{Contribution of this paper to the literature}

- In this study we analyzed the discursive actions employed by low-achieving students, where this population has not been sufficiently studied before regarding their learning routines.

- This study contributes to literature on how low achieving students use technological tools to learn mathematical concepts. This would help teachers assist low achieving students in their understanding of mathematical concepts.

- Prior research on low achieving students mainly focused on the mental processes of students. This study contributes to the literature by utilizing a relatively new framework which emphasizes social constructivist aspects, what could help understand the students' learning routines in a group.

effective teaching (Ball, 2003) by, for example, the use of questions. By real-context tasks, we mean tasks whose contexts have real-world relationships. In the present research, these principles guided our experimentation design, and the low-achieving participants were given real-context tasks related to mathematical equality to solve. We use the term equality in a broad sense, namely, if the two given numbers are equal we say the equality is true, otherwise we say the equality is false. Concurrently, the students worked with an applet specifically designed to help the learner understand the notion of mathematical equality, which have been indicated to be critical to algebra (e.g., Stacey \& Chick, 2004).

Researchers have been interested, for quite a long time, in students' understanding of mathematical equality and in studying methods to develop students' relational understanding of it. In the present research, we followed these attempts in the case of low achieving students who work with authentic activities and technology. No special attention was given to the equal sign, where our activities were related to equality as an entity. Understanding that equality refers to a relationship between quantities is an important part of one's conceptual understanding of the mathematical notion of equality. Notwithstanding its importance, however, the notion of equality is often too complex and difficult for some students to grasp (Knuth et al., 2008). This observation and the integral relationship that equality has with more advanced mathematical concepts (e.g., equations, functions) motivated researchers to investigate students' understanding of equality. Although a plethora of such research exists on pupils at the elementary school level, less is known about students' understanding of the notion of equality beyond the elementary school years (McNeil et al., 2006), particularly as this concerns low-achieving students. This state of art is especially true for the use of technological tools among low-achieving students in real-context tasks to learn about equality. In this study, we attempt to examine how low-achieving students understand equality and inequality through their interactions with a dynamic tool that simulates a two-pan balance scale.

\section{LITERATURE REVIEW}

\section{Students' Learning of Mathematical Equality}

Knuth et al. (2008) examined how middle school students (grades 6-8) defined the equal sign. They reported that in the sixth and seventh grades, more pupils offered operational definitions than relational definitions. However, although among the eighth grade students the percentage of pupils who described the equal sign via a relational definition was higher, nevertheless 45 percent of them still gave operational definitions. A subsequent finding of this study was that students whose notion of the equal sign was based on a relational definition were more likely to solve algebraic equations correctly than students whose definitions of the concept were operational (i.e., the equal sign means "add the numbers" or "the answer"). In their study of students' conceptual understanding of equivalence, McNeil et al. (2006) reported that instead of interpreting the equal sign as a relational symbol of mathematical equivalence, most elementary school students construe it as an operational symbol that means, e.g., "find the answer". Similar findings were reported by other researchers (Powell, 2012; Sherman \& Bisanz, 2009), some of whom argue that to thoroughly understand the notion of equivalence, the conceptual challenge must be overcome, namely, the relational understanding of mathematical equality should be developed (Zwetzschler \& Prediger, 2013).

Accordingly, several researchers have opined that helping students acquire relational understanding of mathematical equality will facilitate their success in algebra and beyond (e.g., Hunter, 2007; Knuth et al., 2008). Generally speaking, the mathematical equality - and the related notions of equivalence and equation - are complex and difficult for students to understand (Hunter, 2007; Kieran, 1981). McNeil and Alibali (2005) showed that students in middle school do not tend to exhibit a relational understanding of the equal sign unless they have the necessary contextual support. Given that students' interpretations of the mathematical equality are likely to be shaped by context, McNeil et al. (2006) recommended that researchers try to determine which contexts, if any, are most likely to cultivate the relational understanding of mathematical equality in students. 
In the educational context, the teacher and his/her instruction have together long been identified as playing a central role in promoting the relational understanding of mathematical equality. Denmark, Barco, and Voran (1976) designed a teaching experiment in which the notion of mathematical equality was the focus. These researchers concluded that instruction design was a contributing factor behind whether students understood the relational understanding of the mathematical equality. Wolters (1991) reported that students whose instruction included different activities - i.e., concrete manipulation, perceptual representation and abstract symbolism - demonstrated better relational understanding of the mathematical equality than their counterparts. In their year-long study, a socio-constructivist experiment with third graders, Saenz-Ludlow and Walgamuth (1998) found that the combination of an interactive teacher instruction style with active pupil participation in a constructivist framework helped the study participants expand their conceptualizations of equality. Indeed, Freudenthal (1991) describes the importance of the teacher's instruction in terms of his/her intellectual sensitivity to "strike a delicate balance between the force of teaching and the freedom of learning" (p. 55).

In light of the literature reviewed above, we designed a learning environment that contained a dynamic tool for learning the mathematical equality. In addition, we designed learning tasks guided by the principles of a relational understanding of the notions of mathematical equality and inequality and of effective teacher instruction as reviewed above.

\section{Low-achieving Students' Learning of Mathematics}

How low-achieving students learn mathematics has attracted the attention of scholars for decades. Often perceived as only being capable of working according to efficient procedures or techniques that lead to a correct solution, low achievers usually adopt short problem-solving processes. Moreover, they use a single solution method to tackle a problem and they reach rapid decisions, but they also give up quickly in the event that they fail to solve the problem (Cardelle-Elawar, 1995; Yerushalmy, 2006). Researchers have also focused intensively on the cognitive deficiencies and on the behavioral manifestations of the failures of low-achieving students. For example, Geary (2004) found that it is difficult for low-achieving students to create mental images for mathematical concepts. Gray, Pitta and Tall (2000) observed that low-achieving students usually have difficulty when they try to retrieve basic mathematics knowledge from their memories. Researchers also found that these students lack metacognitive skills (Goldman 1989) and that they are sensitive to the learning context. Moreover, even simple addition and subtraction problems are much more difficult to solve for low achievers than for normal students (Broza \& Ben David - Kolikant, 2015). The classroom experiences of low-achieving students, therefore - often characterized by repeated failure and difficulty keeping pace with the class - constitute a scenario that can ultimately sap their motivation to learn and cause them to give up quickly at the first sign of difficulty in the learning process (Haylock 1991).

Despite the formidable learning challenges that confront low-achieving students, however, research also shows that they are capable of improving their mathematical understanding. Karsenty, Arcavi and Hadas (2007) and Chazan (2000) found that low-achieving students can express mathematical reasoning orally when they learn in a supportive learning environment, such as small groups. In addition, technological tools were also suggested to be a viable means through which to support low-achieving students' learning of mathematics. Yerushalmy (2006) found that they were capable of using graphing software to confirm conjectures, to complete difficult mathematical operations and to obtain a broader view of a given mathematical situation. Moreover, the processes they exploited to reach solutions were relatively long, and their solution strategies were overly focused on numeric and graphic representations, which delayed their development of an understanding of symbolic formalism. Likewise Peltenburg (2012) showed that when low-achieving students used computerized tools, they were able to solve subtraction problems by spontaneously using an indirect addition strategy rather than the conventional, direct subtraction strategy. Moyer-Packenham and Suh (2012) investigated the influence of virtual manipulatives on groups with varying levels of achievement who learned about fraction equivalence and the summing of fractions with unlike denominators. The results of their research indicated that the low-achieving group relied heavily on the pictorial models in the applets, where they engaged in multiple trial and error interactions with the pictorial and symbolic features to complete mathematical tasks. Specifically, they used a step-by-step process to find multiples and common denominators, they used counting strategies rather than proportional relationships, they did not recognize equivalence relationships, and they were confused by the notion of the common denominator.

Researchers who study learning behavior posited that low-achieving students need more specialized instruction than do their peers (Vukovic \& Siegel, 2010). They demonstrated that low-achieving students benefit from explicit instruction (e.g., Fuchs et al., 2008; Jitendra et al., 2009) and from instruction that connects mathematical concepts and procedures (Miller \& Hudson, 2007). Additionally and importantly, to facilitate the students' understanding of mathematical concepts, teacher intervention is critical.

The studies cited above illustrate the benefits and limits for low-achieving students in learning mathematics with technology. We believe that when low-achieving students learn in an environment that is meaningful for them 
and that includes, among other things, technology, they will be more capable of independently making meanings for mathematical objects and relations.

\section{A Productive Environment for Students' Learning of Mathematics}

The difficulties typically encountered by students in their initial attempts to comprehend mathematical concepts can be lessened in a learning environment that incorporates authentic tasks (Taylor-Cox, 2003) and technology (Jones \& Pratt, 2006) and that is under the guidance of the teacher. The use of technology to assist in learning about equality was reported on by Jones and Pratt (2006), who conducted an experiment in which two students connected an onscreen ' $=$ ' object with other arithmetic objects in an exercise designed to help them develop a relational understanding of mathematical equality. The utility of implementing real-context activities to facilitate learning of mathematical equality was investigated by Taylor-Cox (2003), who used a pan balance scale to visually demonstrate equality. For the combination of authentic tasks with technology to reliably foster learning of the relational understanding of mathematical equality by the students, however, requires the guidance of a teacher. Indeed, researchers have indicated the importance of the teachers' guidance in general when learning mathematics (NCTM, 2000) and particularly when learning the mathematical equality (e.g., Taylor-Cox, 2003). For example, in describing how mathematics teachers can enhance their students' learning, Taylor-Cox (2003) claims that the teacher's role is to ask questions that promote mathematical dialogue and understanding. As such, the mathematics teacher's actions are part of the classroom routines (using Sfard's terms) that foster mathematics learning among the students.

In light of the above, we designed the learning environment while taking into consideration the roles of technology and of the teacher as well as the types of tasks the students would be asked to perform. To better understand students learning in this environment, we analyzed students' progress by using Sfard's commognition framework with a particular emphasis on how the use of routines evolved. In the following section, we outline the commognition framework.

\section{THEORETICAL BACKGROUND - THE COMMOGNITION FRAMEWORK}

The commognition framework developed by Sfard (2008) to analyze and understand how students learn mathematics incorporates four components of the mathematical discourse that contribute to its analysis: words, visual mediators, narratives and routines. Mathematical words are used by the participants in a mathematical discourse to express their mathematical ideas and to communicate with each other about them. In this discourse, students not only learn new uses of previously encountered mathematical words, they may also learn completely new words that are unique to mathematics. Visual mediators are visual objects that participants of mathematical discourses use to identify mathematical ideas. They include symbols such as numerals, algebraic letters, tables, graphs and diagrams. A narrative is a spoken or written text that describes objects or relations between objects or activities with or by objects and that could be accepted or rejected within the mathematical discourse. Examples of narratives in mathematics could be theorems, definitions and equations.

The construction of narratives entails working with mathematical signifiers - in our case, the mathematical equality - and their realizations. According to Sfard (2008), a "Realization of the signifier S is a perceptually accessible thing $S^{\prime}$, so that every endorsed narrative about $S$ can be translated according to well defined rules into an endorsed narrative about $S^{\prime \prime \prime}$ (p. 154). Furthermore, she says that realizations can take the form of spoken or written words, algebraic symbols, drawings, concrete objects, or gestures. She further argues that the discursive transition from signifier to its realization may be immediate (as when the signifier is "Function g" and the realization is its "Table of values") or it may be mediated by a realization procedure (as in the case when the signifier is "slope of $\mathrm{g}$ " and its realization is " 5 "). Moreover, working with and manipulating the realizations of $S$ is a principal method for constructing endorsed narratives about $S$.

Sfard (2008) defined routines as "repetitive patterns characteristic of the given discourse" (p. 134). They are characterized by the use of mathematical words and visual mediators or the creation, substantiation or change of mathematical narratives. Examples of typical mathematical routines are methods of calculation and of proof (Sfard, 2008). Sfard divides routines into explorations that aim to promote further discourse by producing or verifying endorsable narratives (such as verifying a mathematical conjecture or proving a mathematical relation); deeds that aim to change the actual objects, physical or discursive, and not just the narratives; and rituals that are implemented to create and sustain social approval with other participants in the mathematical discourse and that could involve imitations of other participants' routines (Berger, 2013). In addition, Sfard further divided explorations into construction that creates new, endorsable narratives, substantiation that is used to decide whether to endorse previously created narratives, and recall for summoning narratives endorsed in the past. 


\section{RESEARCH RATIONALE AND GOALS}

While researchers interested in studying the conceptual understanding of mathematical concepts among lowachieving students have focused extensively on cognitive research from a Piagetian point of view, few have examined, from the commognition point of view, the learning of mathematical concepts and relations by lowachieving students. One such attempt is that of Ben-Yehuda, Lavy, Linchevski and Sfard (2005), who used the commognition framework to study the mechanisms of failure in the mathematics performances of two 18-year-old girls with long histories of learning difficulties. They concluded that almost any person may become a skillful participant of arithmetical discourse provided that, first, a discursive mode is found that effectively leverages the individual's unique strengths and that, second, in the process of teaching, the teacher acknowledge the general sociocultural context of learning as occupying a central role in enabling or barring one's access to literate discourses. They also concluded that if the potential for successful participation remains unrecognized, it is mainly because of certain, widely practiced abuses of literate mathematical discourse. Thus, our analysis of mathematics learning from the perspective of the commognition framework helps account for, on the one hand, the general sociocultural context of learning and, on the other, the communication aspects of learning. Taking these aspects of the mathematical discourse into account helps us, in turn, understand how students grasp mathematical objects (Sfard, 2008). In our design of mathematical activities for low-achieving students' learning of the notion of mathematical equality, therefore, we took the sociocultural context of their learning activities into consideration.

The present study was designed to examine the routines followed by low achieving students in their attempts to realize the notion of mathematical equality while using technological tools. The results of this study will enable us to verify whether, in their daily mathematics work, low-achieving students tend to follow only ritual routines or whether they can also engage in construction routines to realize mathematical concepts.

\section{METHODOLOGY}

\section{Research Context}

As mentioned above, the study is framed in a sociocultural context. The students worked in pairs, each of which shared a single computer for the duration of the experiment. The learning process was mediated by the teacher, who asked questions and guided the students' learning, and it involved the participants' use of an interactive, educational applet named Pan Balance - Numbers (PBN; NCTM, 2015; Figure 2). The PBN applet comprises a computerized simulation of a culturally based artifact, namely, the two-pan balance scale, which today is still in use in the students' real world. Furthermore, the task design entailed operations relevant to the students' culture, such as weighing and comparing quantities.

\section{The Technological Tool Used in the Study}

As described above, the technological tool used in our study was the interactive PBN applet (NCTM, 2015; Figure 1). The interactive PBN allows numeric expressions to be entered and compared. Students can "weigh" the numbers they want to compare by typing them in numeric fields on the sides of the pan balance. Using this interactive applet, students can investigate the equivalence of the expressions in the two pans. The PBN interface consists of three main sections a) the pans, where users enter the numbers and expressions they wish to compare; b) the keyboard, which enables the student to enter and edit the expressions in the pans; and c) the table of values, which displays the pairs of equal numbers and expressions entered in the pans. If the student enters two equal expressions in the two pans of the balance, the applet will display a numeric equality on the table of values which is in the upper-right side. However, the applet will display nothing on the table of values if the expression entered into the two pans are not equal (Figure 1). 


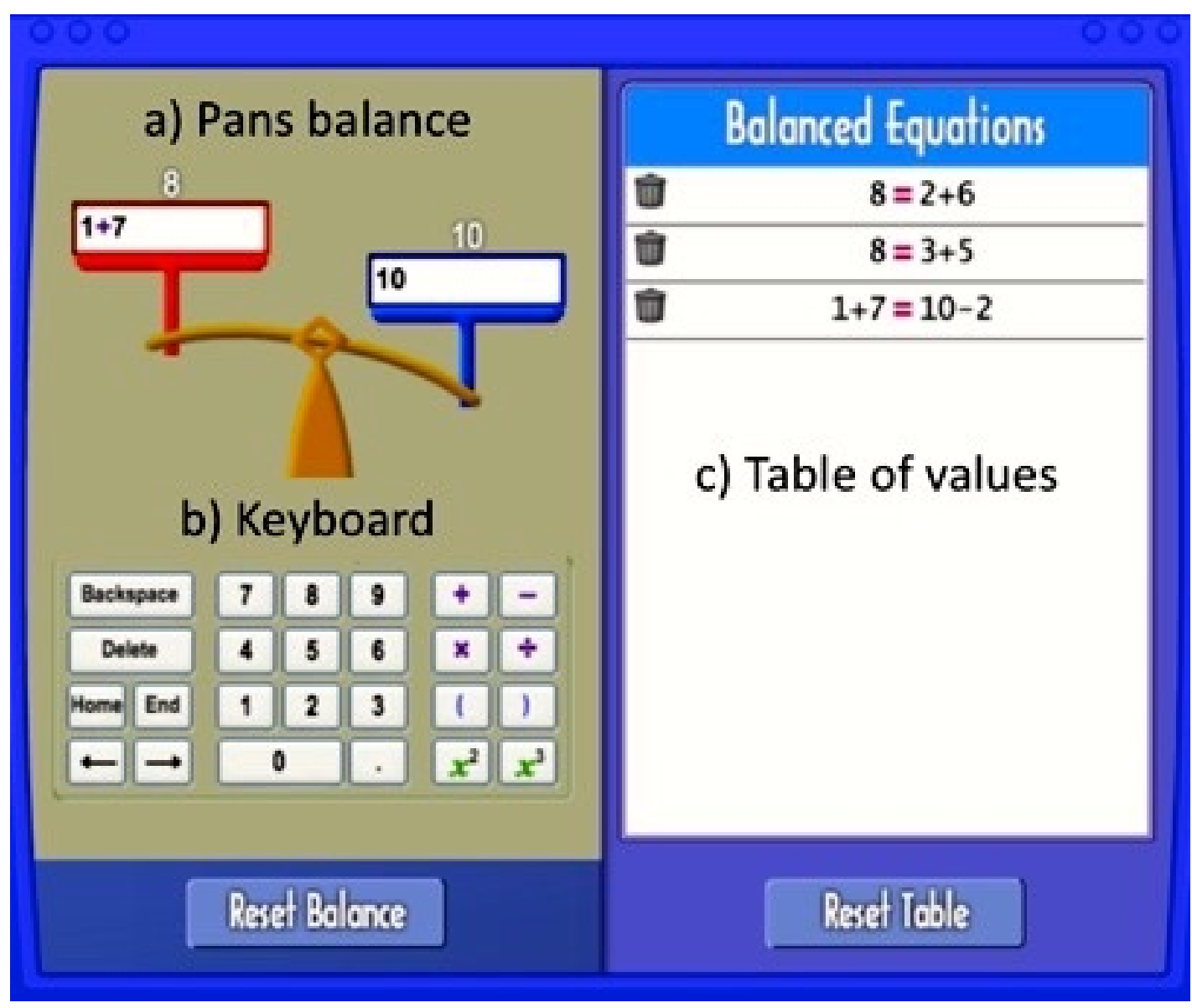

Figure 1. Pan Balance - Numbers interface

\section{The Activity}

The experimental activity was designed according to the principles mentioned above, namely, to support the interpretation by low-achieving students of the notion of mathematical equality as a relationship between quantities rather than as a procedure for 'find the answer'. In addition, the activity was framed in the real context of the pan balance that was embedded in a technological tool that allowed the students to manipulate it and experiment with the notions of mathematical equality and inequality. We expected that the principles satisfied by the activity would foster an understanding of the relational understanding of notion of mathematical equality among the low-achieving students.

The activity comprised nine question items as follows. 
1. What happens if we put 4 in the red pan and 9 in the blue pan? Why?

2. Put other numbers in the two pans. What happens? Why?

3. What happens if we put 12 in the red pan and two numbers whose sum is 12 in the blue pan? Why?

4. Can you find another pair of numbers whose sum is 12? Explain.

5. Can you use another arithmetic operation to make 12? Explain.

6. Can you find three numbers with arithmetic operations that make 12? Explain.

7. Can you find four numbers with arithmetic operations that make 12? Explain.

8. Can you put one set of numbers in the red pan and another set of numbers in the blue pan such that the pans will balance?

9. Can you put one set of numbers in the red pan and another set of numbers in the blue pan such that the pans will not balance?

Figure 2. The activity given to the students

The equality states of the pan balance in the first two items expose the students to the notions of mathematical equality and inequality. The third and fourth items utilize the pan balance equilibrium states to engage the students in realizing the mathematical equality when just one pan (one side of the equality) has a sum of numbers. The fifth to the seventh items help the students in realizing the mathematical equality which can contain sets of numbers with different arithmetic operations in one pan (i.e., one side of the equality) and only one number (12) in the other pan (the other side of the equality). The eighth item engaged the students in realizing the mathematical equalities which contain one set of numbers and arithmetic operations in each pan (each side of the equality). The ninth item engaged the students with realizing the mathematical inequalities which have one set of numbers and arithmetic operations in each pan (each side of the inequality).

Our choice to expose the low-achieving students to a variety of realizations for the signifier of mathematical equality while focusing on a single case of 12=12 followed, in part, the work of Powell (2012), who recommends that students be exposed to a variety of equation types to promote a relational understanding of equality. Our restriction of the activity to the special case of 12 was after Zwetzschler and Prediger (2013), who recommend limiting the degrees of generality for variables.

\section{Participants}

The experiment took place at a vocational high school for low-achieving students where the pupils learn trades such as car mechanic and house/car electrician. Three pairs of 16-year-old, low-achieving students volunteered to participate in four afterschool meetings designed to prompt the relational understanding of equality notion. In this study, we concentrated on the first meeting, which dealt with learning that the mathematical equality is a relationship between two quantities rather than an operational conception of equality. The students participating in this study had been considered low-achieving in higher grades of the primary school and in the middle school. These low achieving students have a special curriculum that emphasis basic skills in mathematics. In more details, the participating students, according to the teacher testimony, mainly mastered basic arithmetic operations (addition, multiplication, subtraction, and basic division) and the equal sign as an operational conception. The students who participated in the study were not familiar with using technological software to learn mathematics. Each pair of students shared a single computer, and the teacher briefly introduced them to the functions of the software before beginning the experimental activity.

\section{Data Collection}

While the students performed the activities, they and their computer screens were video-recorded. The video recording was done with a computer program that captured the footage in two different windows, one each for the computer screen and for the student. The teacher conducted the learning activity, where his main role was to ask clarification questions. Each pair of students carried out the task presented in Figure 1. To answer the research question, we analyzed approximately three hours of learning for each pair of 16-year-old, low-achieving students who participated in the research. 

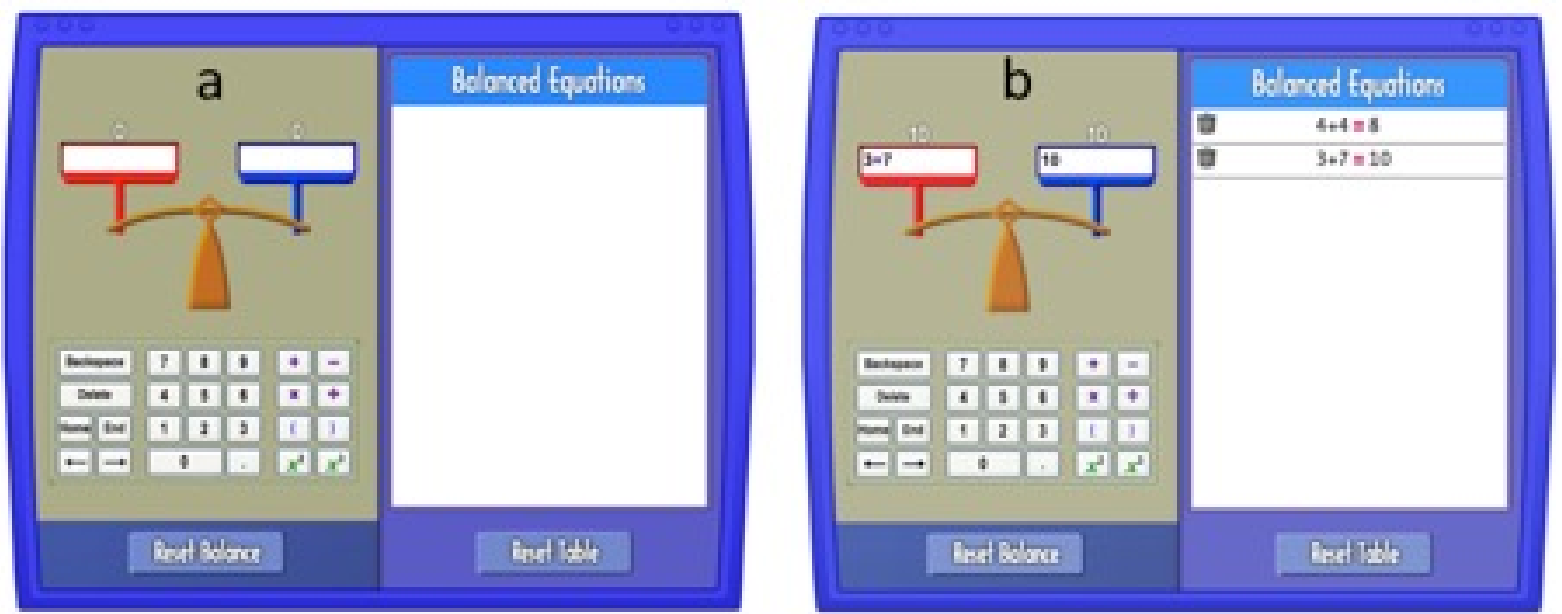

Figure 3. a) Default applet interface and b) an example of equilibrium state of the balance

\section{Data Analysis}

The data analysis began with watching the videos repeatedly, transcribing them, and reading the transcripts. Next, we analyzed the transcripts while focusing on the routines that the students performed and the realization processes they implemented when performing those routines. We categorized the routines according to the types as suggested in Sfard (2008). We considered a routine to be an exploration when the student's goal in performing the routine was to establish a narrative. We considered a routine to be an exploration of the type 'construction', when its goal was to endorse a mathematical narrative or to verify a relationship that was arrived at or conjectured.

To analyze the transcripts in terms of the signifiers and realizations of the notion of mathematical equality, we initially analyzed what we termed the signifying and realization potential of the simulated pan balance in regard to notion of mathematical equality. Thereafter, we categorized the transcripts according to this potential. Specifically, the applet enabled the students to work with different signifiers and their realizations concerning the notion of mathematical equality to understand what the notion means.

In more detail, regarding the signifying and realization potentials of the simulated pan balance, this pan balance could be considered to be a signifier of mathematical equality and inequality. As such, the students' interaction with the pan balance was expected to help them through the process of signifying the notion of mathematical equality. We expect that the pan balance would help the students in evaluated if an equality is true or false for the particular numbers involved. Here, we use the term equality in a broad sense, namely, if the two given numbers are equal we say the equality is true, otherwise we say the equality is false. In the default interface of the applet, the 'table of values' appears as a blank screen (Figure 3a). Only after the student enters equal values in the two pans of the balance is the table of values displayed. Note that even when the applet displays the table of values, it also continues to display the pan balance on the upper left side of the interface (Figure 3b), which makes the pan balance the most salient feature of the interface for the user (Kress \& van Leeuwen, 1996). Figure 3a shows the applet's default starting interface, and Figure $3 \mathbf{b}$ shows the applet's interface after the realization $3+7=10$ has been obtained.

We anticipated that insofar as it is a salient component of the interface and related to their real-world experiences, the pan balance, a signifier of mathematical equality or inequality, will attract the attention of the students first. Likewise, we expected that as the students work with the pan balance, its dynamic nature will prompt them to explore the mathematical equality, and we expected the students to make several trials to obtain different realizations of mathematical equalities and inequalities.

Working with the applet, the students make the transition from an equilibrium state of the pan balance, i.e., the signifier, to a pair of equal values in the 'table of values', i.e., the realization of the signifier. We expected that the applet's design enables the simultaneous display of the pairs of equal values in the table of values and of the equilibrium state of balance. This simultaneous display of both the signifier and its realization may promote awareness in the students of the relationship between the equilibrium state of the pan balance and the pairs of the equal expressions in the table as signifying mathematical equality. We assume that this awareness is more advanced than being involved only with the equilibrium state of the pan balance as signifying the notion of mathematical equality. This is because it leads to new meanings of this notion; namely, the signifier-realization relationship between the equilibrium state of the pan balance and the pairs of equal values in the table of values. 
In addition to being involved in the transition from the pan balance to the table of values, the student who works with the applet could be involved in the other direction transition, i.e., from a pair of equal values in the table of values as signifier into an equilibrium state of pan balance as appropriate realization. This transition involves not only the transition from pairs of equal values, but also the transition, from pairs that are not appearing in the table, into their realization as disequilibrium state of pan balance. This transition may help the students in signifying the mathematical equality in its two truth values (true/false). For example, the student working with the applet, could start from the equality, $4+4=8$, in the table of values, realize it as equilibrium of the pans. The students could also get involved in signifying the inequality between values which are not displayed in the table of values (e.g., 4+4>7) and realize them as disequilibrium of the pans.

\section{RESULTS}

\section{Realizing the Notion of Mathematical Inequality by Disequilibrium State of the Pan Balance}

At the start of the experiment, the students focused on the disequilibrium state of pan balance as a signifier the notion of mathematical inequality. The students then entered different numbers in the two pans, and the pan with the larger value descended. This action drew the students' attention to the inequality between the numbers. They realized the notion of mathematical inequality using daily words such as "it went down".

\begin{tabular}{lll}
\hline 10 & Teacher & Put four in the red pan and nine in the blue pan. What happened? \\
\hline 11 & Najd & [She places the mentioned values in the pans]. The pan balance went down. \\
12 & Mosa & $\begin{array}{l}\text { [Looking at the pan balance] Because of nine, it went down, and because of four, it went up. } \\
\text { nine is heavier than four. }\end{array}$ \\
\hline 13 & Teacher & How do you recognize that? \\
\hline 14 & Mosa & Because of nine, it [the pan balance] went down and because of four, it [the pan balance] went up. \\
\hline 15 & Najd & Because nine is bigger than four.
\end{tabular}

This excerpt illustrates the development of discursive actions related to the realization process undergone by Najd and Mosa, in which they realized the disequilibrium state of the pan balance as a signifier of mathematical inequality. In line [11], Najd performed a ritual routine as she fulfilled the teacher's request [10] to enter the values in the pans. Then she constructed a narrative as she observed the state of the pan balance, which constituted a signifier of the notion of mathematical inequality that Najd realized with the daily words "the pan balance went down". In line [12], Mosa performed a substantiation routine - he substantiated Najd's narrative - by saying "Because of nine, it went down, and because of four, it went up. nine is heavier than four." The substantiation performed by Mosa, however, is still in daily terms. Following Mosa's substantiation routine, Najd performed a related substantiation using mathematical terms: "because nine is bigger than four."

\section{Realization of Pan Balance Signifiers of Equality with Pairs of Equal Numbers in the Table of Values}

The excerpt below from the experiment transcript depicts the engagement of the students with the signifiers of equality, which emerged as a result of the students' work with the pan balance and the pairs of equal values in the table as their realizations. This engagement occurred in response to the teacher's intervention, in which he prompted their attention to the realizations in the table of values.

\begin{tabular}{lll}
\hline 55 & Teacher & $\begin{array}{l}\text { I suppose you noticed that when you get equilibrium in the pan balance, the applet keeps } \\
\text { the numbers. Can you give me all the cases that give 12? }\end{array}$ \\
\hline 56 & Mosa & $\begin{array}{l}\text { Twelve and twelve have equilibrium. They are the same. [Mosa points at the pair of } \\
\text { numbers } 12 \text { and } 12 \text { in the table of values] }\end{array}$ \\
\hline 57 & Teacher & What else? \\
\hline 58 & Mosa & Six and six \\
\hline 69 & Mosa & Ten and two, and seven and five. \\
\hline 61 & Mosa and Najd & We can transform the number twelve in more than one way into other things. \\
\hline 62 & Teacher & Like what? \\
\hline 63 & Mosa and Najd & One plus eleven, three plus nine. There are many things. \\
\hline 64 & Teacher & What happens in all these cases? \\
\hline 65 & Mosa & Straight because the same number results.
\end{tabular}


The teacher drew the students' attention to the equal numbers in the table of values [55]. The students' usage of the word "balanced" [56] indicates that they were aware that the pairs of equal numbers in the table of values were realizations of the equilibrium states of the pan balance which signifies mathematical equality. In the previous engagement, the students were engaged first in ritual routines [56-59] via their compliance with the teacher's request and their reading of the equalities in the table of values. Following the teacher's intervention, the wording of which was intentionally general to elicit from the students generalizations about what they had learned [60], the students switched from ritual routines to construction $[61,63]$. The students constructed the narrative "We can transform the number twelve in more than one way into other things" [61]. In line [64], the teacher again intervened, but this time he drew the students' attention to the pan balance realizations of the pairs of equal numbers in the table of values as signifiers of mathematical equality. As a result, the students substantiated their previous narrative by referring to the pan balance being in equilibrium and by using the term 'straight' to indicate the state of this equilibrium [65]. The students use of the term straight (i.e., the pan balance is level) suggests that they still utilize daily terms to realize the mathematical equality.

The other two pairs of student participants engaged in similar realizations, namely, they realized the signifiers of the pan balance with the pairs of equal numbers in the table of values. Below is an excerpt of the work of Ahed and Saed (another pair of students who participated in the research) from their participation in the same activity described above.

\begin{tabular}{lll}
\hline 14 & Teacher & $\begin{array}{l}\text { Put twelve in one of the pans and two numbers whose sum is twelve in the second pan. What } \\
\text { happens and why? }\end{array}$ \\
\hline 15 & Ahed & [He put 12 in the red pan and $8+4$ in the second pan.] \\
\hline 16 & Teacher & What happened? \\
\hline 17 & Ahed & [He pointed at the pans] They balanced. Twelve is equal to twelve [He pointed at the equality] \\
\hline
\end{tabular}

In the above excerpt, one of the students moved the cursor from the pan balance to the pairs of equal numbers in the table of values, saying 'balanced' when pointing at the pan balance and 'equal' when pointing at the equality in the table of values. These actions suggest that Ahed and Saed realized pan balance signifiers with the pairs of equal numbers in the table of values without the intervention of the teacher. In contrast, the realization by the first group happened only after the teacher prompted the students to realize the equilibrium states of the pan balance with the pairs of equal numbers in the table of values.

\section{Realization of Pairs of Equal Numbers in the Table of Values with Pan Balance Equilibrium}

The following excerpt from the experiment transcript illustrates the students' routines when they realized the pairs of equal numbers in the table of values (i.e., signifiers of mathematical equality) with the equilibrium states of the pan balance. This realization was prompted by the teacher's reference to the sets of numbers in the table of values [258].

\begin{tabular}{lll}
\hline 258 & Teacher & $\begin{array}{l}\text { We want to use a set of numbers and arithmetic operations that give twelve in the red pan and in } \\
\text { the blue pan. You can use the sets in the table of values. }\end{array}$ \\
\hline 259 & Najd & [She entered in the red pan: $5+5+2]$ \\
\hline 260 & Mosa & $\begin{array}{l}\text { [He entered in the blue pan: } 7+10-5] \text { five plus five plus two is balanced with seven plus ten } \\
\text { minus five. }\end{array}$ \\
\hline 261 & Teacher & How did we know that they are balanced? \\
\hline 262 & Najd & Because these numbers are in the pans and the pans got balanced. \\
\hline 263 & Teacher & You saw here twelve and here twelve, and the pans balanced. \\
\hline 264 & Najd & The numbers influence the equality. \\
\hline 265 & Teacher & What do you mean? \\
\hline 266 & Najd & $\begin{array}{l}\text { We put in the red pan five plus five plus two. This gives twelve. We put in the blue pan seven } \\
\text { plus ten. This gives seventeen, minus five. It gives twelve. }\end{array}$ \\
\hline 267 & Teacher & You mean you did the computations in your mind. \\
\hline 268 & Mosa & Yes, we also looked at the pans, how they balanced. \\
\hline
\end{tabular}

At the beginning of the above excerpt, the students were prompted by the teacher to realize the pairs of equal numbers in the table of values with the equilibrium states of the pan balance [258], which they did (see lines [259260]). During this realization process, the students performed various discursive routines, such as the deed routine executed by Najd and Mosa in lines [259-260]. Mosa entered an expression in the right pan that equals the expression entered by Najd in the left pan. This deed routine was also part of a construction routine [260], in which 
the students constructed an endorsed narrative regarding the equality between two expressions "five plus five plus two is in equilibrium with seven plus ten minus five". Following the teacher's intervention [261, 263, 265], the construction routine developed into a substantiation routine [262-268], where the students explained why the two expressions in the two pans are equal. In this substantiation routine, the students realized the equilibrium states of the pan balance with pairs of equal values [264, 268] and vice versa [263, 266].

In the following excerpt, the students focused their attention on the table of values alone. They identified the pairs of values in the table of values as realizations of the same signifier, namely, 12.

\begin{tabular}{lll}
\hline 272 & Teacher & Let us look at the table. What do you notice? \\
\hline 273 Mosa & $\begin{array}{l}\text { Eight plus four equals twelve, fifteen minus three equals twelve, six times two equals twelve, } \\
\text { three plus seven plus two equals twelve. }\end{array}$ \\
\hline 274 & Teacher & So, what do you conclude? \\
\hline 275 & Najd & $\begin{array}{l}\text { Many numbers give twelve. All the operations in the table give twelve. Equalities depend on the } \\
\text { numbers and the operations. }\end{array}$ \\
\hline 276 & Mosa & Because all, after the operations, return to be twelve. \\
\hline
\end{tabular}

The teacher [272] prompted the students to consider the pairs of values in the table of values. The students immediately mentioned several arithmetic operations that result in 12 [273], indicating that they identified a variety of numbers and operations as realizations of the signifier 12. The teacher's subsequent prompts [274] engaged the students with several realizations of the signifier 12 [275-276].

\section{Realization of the Notion of Mathematical Inequality}

In the following excerpt, the students focused on the notion of mathematical inequality and shifted their discourse accordingly from equality to inequality.

\begin{tabular}{lll}
\hline 283 & Teacher & $\begin{array}{l}\text { We want to put one set of numbers in the red pan and another set of numbers in the blue pan, so } \\
\text { that the pans will not balance. }\end{array}$ \\
\hline 284 & Najd & To be different? \\
285 & Mosa & $\begin{array}{l}\text { We put in the left pan twenty four divided by two equals twelve, and in the right pan eight times } \\
\text { two equals sixteen. The scale did not balance because those in the right pan are bigger than those } \\
\text { in the left pan. }\end{array}$ \\
\hline 286 & Najd & These are not displayed in the table \\
\hline 287 & Teacher & What do you mean? \\
\hline 289 & Najd & The table has only equalities. The scale has not just equalities. \\
\hline 290 & Mosa & $\begin{array}{l}\text { What do you conclude? } \\
\text { not in the table. Five plus twelve is bigger than six plus four. These are not in the table and give } \\
\text { unbalanced in the pan balance. }\end{array}$ \\
\hline
\end{tabular}

Until this point in the experiment, students focused only on the numbers displayed in the table of values, i.e., signifiers of equilibrium states of the scale. Here, however, the students began to realize that the pairs of numbers that they entered but that were not displayed in the table of values constitute signifiers of disequilibrium states of the scale [285-286]. In line [285], Mosa performed a deed routine, i.e., he entered an expression in the right pan that was greater than the expression in the left pan. In light also of Najd's utterance in line [284], this deed routine marked the beginning of a construction routine in which the students constructed an endorsed narrative regarding the inequality between two expressions. The teacher's question [287] required that the students elaborate, which prompted them to engage in a construction routine of the signifiers of inequality [288]. On the other hand, the teacher's question [289] required the students to conclude about the inequality, which helped them construct and substantiate the narrative: "There are many numbers and operations that give us unbalanced states in the scale, which are not in the table."

The realization of pairs of numbers that are not displayed in the table of values as signifiers of disequilibrium states of the scale also occurred in the two other groups in a similar manner, i.e., after the teacher asked the students about the link between the pairs of numbers that were not displayed in the table of values and their realizations in terms of the equilibrium state of the pan balance.

The student participants in the other two groups exhibited similar discursive actions in their attempts to realize the inequality signifiers. As such, they began by performing deed routines that - because they were performed to comply with the teacher's requests and questions - were also ritual routines. They turned into a construction routine following the teacher's request for explanation, generalization and conclusions. Finally, the students also substantiated narratives using the pan balance. 


\section{DISCUSSION}

The present study aimed to analyze low-achieving students' discursive actions, using the commognition framework (Sfard, 2008), as they learned about the notions of mathematical equality by using a dynamic and interactive technological tool. We were interested that student will develop conceptual understanding of the mathematical equality and the equal sign. The students in this study had already the operational understanding of equal sign so we expected, that working with the artifact would develop this operational understanding into a relational one. The research results indicate that the participants succeeded in realizing signifiers of the notions of mathematical equality and inequality as equivalence relations. To do so, the students utilized the significance and realization potentials of the applet. The teacher's prompts, in the form of questions and requests, played an essential role in prompting the students to pursue signification and realization of the notions of mathematical equality and inequality, as they grappled with these notions.

Student interaction with the applet was driven by its signification and realization potential, which rely on the signifiers and their realizations and the extent to which the relations between them engage the students and help them realize the signifiers of a mathematical object or relation. In the present study, the students used the two-pan balance or scale as a signifier of equality or inequality via its equilibrium and disequilibrium states. To do so, they entered numbers in the pans of the scale and then observed its resulting equilibrium states. These equilibrium realizations signified, both visually and numerically, the notions of equality and inequality.

In addition, the simultaneous display of the equilibrium states and the related pairs of numeric expressions in the table of values encouraged the students to the equilibrium state (as a signifier of equality) with pairs of numeric expressions, i.e., with equalities that contain numbers. In addition, as the learning process progressed, this table of values was used by the students to realize the inequality signifiers not displayed in the table of values with disequilibrium states of the pan balance. Finally, the students realized the pairs of equal numeric expressions in the table of values were specific mathematical equalities (i.e., the students identified that several numeric expressions as realization of a single signifier (12) of the equality notion). These findings are in accordance with Sfrad's claim that "Often, the realization of one signifier may be necessary for the realization of other ones." (Sfard, 2008, p. 155). Here the realization of the dis-equilibrium states as signifying the notions of equality and inequality was necessary for the students to identify the equal pairs of expressions in the table of values as realizations of the equilibrium states and afterwards, as signifying mathematical equality. The participating students' significations and realizations of the mathematical notions of equality and inequality described above exemplify the signification and realization potential of the artifact - in our study the PBN applet.

The signification and realization potential of the PBN applet that the low-achieving students utilized during the experiment promoted their realization of two signifiers (i.e., the equilibrium states of pan balance and the pair of equal values in the table of values) of the notions of mathematical equality. Identifying each one of signifiers as a realization of the other helped the students realize mathematical inequality not only as disequilibrium state, but also as pairs of numbers that are not present in the table of values. Thus, the students' interaction with the pan balance and the table of values helped them realize the equality as a relationship between quantities (Knuth et al., 2008). It seems that the visual mediation of the pan balance and the multiple examples with which the students worked to carry out the task allowed them to realize the equality as a relationship between quantities. This finding is in line with the results of Yerushalmy (2006), who found that students exploited the graphing software they used during the experiment to support their reasoning and argumentation and to reflect on conjectures. Moreover, she reported that the students typically generated multiple examples with the help of the software until they felt that they had a general explanation of a given mathematical concept, and they recognized the tool's inherent value in promoting their understanding of that concept.

The processes followed by the students during their significations and realizations of the notions of mathematical equality and inequality were characterized by the evolution of their discourse, particularly the commognitive routines they employed. As such, the students began with a deed routine that progressed to a ritual routine and then to a construction routine before proceeding into a daily substantiation routine that led finally to a mathematical substantiation routine. The actions taken by the low-achieving students who participated in this study usually began as a result of the teacher's initiation (e.g., requests), which typically elicited from the students a ritual or a deed routine.

Indeed, the teacher's active involvement in the activity, in the form of his explicit instruction, was essential to prompt the participation of the low-achieving students in signifying the notions of mathematical equality and inequality in their learning. This finding is in accordance with those of other researchers whose studies of the learning of low-achieving students found that they require specialized instruction more than their normal achieving peers (Vukovic \& Siegel, 2010). In the present research, the students benefited from the explicit instruction of the teacher (Fuchs et al., 2008; Jitendra et al., 2009), whose guidance led the students to signify the notions of mathematical equality and inequality. Furthermore, the teacher's guidance of the students throughout the activity 
assisted the latter in connecting the mathematical concepts with their corresponding procedures (Miller \& Hudson, 2007). This happened, for example, when the teacher directed the students to realize the equality signifiers in the equilibrium states of the pan balance with pairs of values in the table of values.

Similarly, the teacher also asked questions that prompted the students to engage with generalization, as e.g., "Many numbers give twelve. All the operations in the table give twelve." As such, the teacher's questions and requests facilitated the students' advancement to substantiation routines, especially when he asked them to explain the narratives they had developed, e.g., when the teacher asked the students why they put specific numbers in the pans of the balance. Moreover, the teacher's questions advanced the students' mathematical thinking on two levels: not only did his questions advance the students' discourse routines, it also helped shift their attention from signifiers to realizations. The latter occurred when the teacher's actions refocused the students' attention on the numeric realizations of the equilibrium states of the balance, which helped the students shift their thinking about the notions of mathematical equality from operational to relational understanding (Zwetzschler \& Prediger, 2013).

\section{CONCLUSIONS}

Sfard (2008) claims that "inspecting or manipulating the structure of realizations of $S$ is one of the principal methods for constructing endorsed narratives about $S^{\prime \prime}$ (p. 155). In our case, the low-achieving students manipulated the pan balance equilibrium and disequilibrium states as realizations of the mathematical notions of equality and inequality, respectively, which helped them construct endorsed narratives about these concepts. The equilibrium and disequilibrium states of the pan balance were particularly salient in their roles as visual mediators, in which they functioned to provide the low-achieving students with visual mediators of the states that were "most liable to investigation and manipulation and may thus lead to endorsed narratives in the immediate way" (ibid, p. 155). Moreover, this manipulability of the mediators helped the low-achieving students realize the equality and inequality signifiers as relationships between quantities.

As we elaborated in the discussion, the teacher played a significant role in supporting the low-achieving students as they signified and realized the notions of mathematical equality and inequality. The teacher's questions and requests prompted the students to endorse and substantiate both the narratives about mathematical equality and inequality and also the realizations of the respective signifiers of the two notions. Finally, insofar as lowachieving students have a greater tendency than normal achievers to give up when they encounter academic challenge, the presence of the teacher and his intervention was especially important to ensure that the study participants persevered and completed the mathematics learning activity of the study (Cardelle-Elawar, 1995; Yerushalmy, 2006).

The results of this study suggest that mathematics teachers of low-achieving students need to accord them close attention when these pupils attempt to realize the signifiers of mathematical objects. In cases where educational artifacts are exploited, teachers should be aware of the signification and realization potential of such artifacts, which will enable them to identify the artifacts with the greatest likelihood of effecting cognitive progress in mathematics students.

Our study provide some evidence that the combination of the signification and realization potential of the educational artifacts, with the teacher's actions, such as her/his requests and questions, help mathematics students, especially those who are considered low-achieving students, realize the signifiers of the mathematical objects with which they were engaged. The exploitation of this approach in the current study enabled the low-achieving student participants to realize notions of mathematical equality and inequality as relationships between quantities. However, the participants (small number of the participant and their grade) of this study are considered one of its limitation. Therefore, to broaden our insight into the impact of the signification and realization potential of the educational artifacts and of the teacher's actions approach ("active" vs. "passive" instruction) on the learning of low-achieving students, further research is needed to be conducted.

\section{REFERENCES}

Ball, D. L. (2003). What mathematical knowledge is needed for teaching mathematics. Secretary's Summit on Mathematics, US Department of Education.

Ben-Yehuda, M., Lavy, I., Linchevski, L., \& Sfard, A. (2005). Doing wrong with words: What bars students' access to arithmetical discourses. Journal for Research in Mathematics Education, 36(3), 176-247. https:/ / doi.org/10.2307/30034835

Berger, M. (2013). Examining mathematical discourse to understand in-service teachers' mathematical activities. pythagoras, 34(1), 1-10. https:/ / doi.org/10.4102/ pythagoras.v34i1.197 
Broza, O., \& Ben-David-Kolikant, Y. (2015). Contingent teaching to low-achieving students in mathematics: Challenges and potential for scaffolding meaningful learning. ZDM, 47, 1093-1105. https:/ / doi.org/10.1007/s11858-015-0724-1

Cardelle-Elawar, M. (1995). Effects of metacognitive instruction on low achievers in mathematics problems. Teaching and Teacher Education, 11(1), 81-95. https:/ / doi.org/10.1016/0742-051X(94)00019-3

Chazan, D. (2000). Beyond formulas in mathematics and teaching: Dynamics of the high school algebra classroom. Teachers College Press.

Denmark, T., Barco, E., \& Voran, J. (1976). Final report: A teaching experiment on equality. Project for the Mathematical Development of Children (PMDC) Technical Report, (6).

Freudenthal, H. (1991). Revisiting mathematics education. Dordrecht: Kluwer.

Fuchs, L. S., Seethaler, P. M., Powell, S. R., Fuchs, D., Hamlett, C. L., \& Fletcher, J. M. (2008) Effects of preventative tutoring on the mathematical problem solving of third-grade students with math and reading difficulties. Exceptional Children, 74, 155-173. https:// doi.org/10.1177/001440290807400202

Geary, D. C. (2004). Mathematics and learning disabilities. Journal of learning disabilities, 37(1), 4-15. https: / / doi.org/10.1177/00222194040370010201

Geertz, C. (1973). The interpretation of cultures. Basic books, New York.

Goldman, S. R. (1989). Strategy instruction in mathematics. Learning Disability Quarterly, 12(1), 43-55. https:// doi.org/10.2307/1510251

Gray, E., Pitta, D., \& Tall, D. (2000). Objects, actions, and images: A perspective on early number development. The Journal of Mathematical Behavior, 18(4), 401-413. https:/ / doi.org/10.1016/S0732-3123(00)00025-0

Haylock, D. (1991). Teaching mathematics to low attainders, 8-12. SAGE.

Hunter, J. (2007). Relational or calculational thinking: Students solving open number equivalence problems. In Proceedings of the 30th annual conference of the Mathematics Education Research Group of Australasia (Vol. 2, pp. 421-429).

Jitendra, A. K., Star, J. R., Starosta, K., Leh, J. M., Sood, S., Caskie, G., \& Mack, T. R. (2009). Improving seventh grade students' learning of ratio and proportion: The role of schema based instruction. Contemporary Educational Psychology, 34, 250-264. https:/ / doi.org/10.1016/j.cedpsych.2009.06.001

Jones, I., \& Pratt, D. (2006). Connecting the equals sign. International Journal of Computers for Mathematical Learning, 11(3), 301-325. https:/ / doi.org/10.1007/s10758-006-9107-6

Karsenty, R., Arcavi, A., \& Hadas, N. (2007). Exploring informal mathematical products of low achievers at the secondary school level. The Journal of Mathematical Behavior,26(2), 156-177. https://doi.org/10.1016/j.jmathb.2007.05.003

Kieran, C. (1981). Concepts associated with the equality symbol. Educational studies in Mathematics, 12(3), 317-326. https:/ / doi.org/10.1007/BF00311062

Knuth, E. J., Alibali, M. W., Hattikudur, S., McNeil, N. M., \& Stephens, A. C. (2008). The Importance of Equal Sign Understanding in the Middle Grades. Mathematics Teaching in the Middle School, 13(9), 514-519. http:/ / www.jstor.org/stable/41182605

Kress, G. R., \& Van Leeuwen, T. (1996). Reading images: The grammar of visual design. Psychology Press.

Leone, P., Wilson, M., \& Mulcahy, C. (2010). Making it count: Strategies for improving mathematics instruction for students in short-term facilities. Washington, DC: National Evaluation and Technical Assistance Center for Children and Youth Who Are Neglected, Delinquent or At Risk (NDTAC).

McNeil, N. M., \& Alibali, M. W. (2005). Knowledge change as a function of mathematics experience: All contexts are not created equal. Journal of Cognition and Development, 6, 285-306. https://doi.org/10.1207/s15327647jcd0602_6

McNeil, N. M., Grandau, L., Knuth, E. J., Alibali, M. W., Stephens, A. C., Hattikudur, S., \& Krill, D. E. (2006). Middleschool students' understanding of the equal sign: The books they read can't help. Cognition and Instruction, 24(3), 367-385. https:/ / doi.org/10.1207/s1532690xci2403_3

Miller, S. P., \& Hudson, P. J. (2007). Using evidence-based practices to build mathematics competence related to conceptual, procedural, and declarative knowledge. Learning Disabilities Research and Practice, 22, 47-57. https://doi.org/10.1111/j.1540-5826.2007.00230.x

Moyer-Packenham, P. S., \& Suh, J. M. (2012). Learning mathematics with technology: The influence of virtual manipulatives on different achievement groups. Journal of Computers in Mathematics and Science Teaching, 31(1), 39-59. 
National Council of Teachers of Mathematics (2000). Principles and standards for school mathematics. National Council of Teachers of Mathematics.

NCTM (2015). Pan Balance - Numbers [computer application]. Retrieved from https:/ / illuminations.nctm.org/ Activity.aspx?id=3530

Peltenburg, M. C. (2012). Mathematical potential of special education students.

Powell, S. R. (2012). Equations and the equal sign in elementary mathematics textbooks. Elementary School Journal, 112, 627-648. https:/ / doi.org/10.1086/665009

Radford, L. (2008). Culture and cognition: Towards an anthropology of mathematical thinking. In L. English (Ed.), Handbook of International Research in Mathematics Education, 2nd Edition (pp. 439 - 464). New York: Routledge, Taylor and Francis. https:/ / doi.org/10.1016/j.cognition.2007.11.014

Saenz-Ludlow, A., \& Walgamuth, C. (1998). Third graders' interpretations of equality and the equal symbol. Educational studies in mathematics, 35(2), 153-187. https:/ / doi.org/10.1023/ A:1003086304201

Sfard, A. (2008). Thinking as communicating: Human development, the growth of discourses, and mathematizing. Cambridge University Press. https:/ / doi.org/10.1017/CBO9780511499944

Sherman, J., \& Bisanz, J. (2009). Equivalence in symbolic and nonsymbolic contexts: Benefits of solving problems with manipulatives. Journal of Educational Psychology, 101(1), 88. https://doi.org/10.1037/a0013156

Stacey, K., \& Chick, H. (2004). Solving the problem with algebra. In K. Stacey, H. Chick, \& M. Kendal (Eds), The future of the teaching and learning of algebra (Vol. 8, pp. 1-20). Dordrecht: Springer. https:// doi.org/10.1007/14020-8131-6_1

Taylor-Cox, J. (2003). Algebra in the early years. Young Children, 58(1), 14-21.

Vukovic, R. K., \& Siegel, L. S. (2010). Academic and cognitive characteristics of persistent mathematics difficulty from first through fourth grade. Learning Disabilities Research and Practice, 25, 25-38. https://doi.org/10.1111/j.1540-5826.2009.00298.x

Wolters, M. A. (1991). The equal sign goes both ways. How mathematics instruction leads to the development of a common misconception. In PME conference (vol. 3, pp. 348-355).

Yerushalmy, M. (2006). Slower algebra students meet faster tools: Solving algebra word problems with graphing software. Journal for Research in Mathematics Education, 37(5), 356-387.

Zwetzschler, L. \& Prediger, S. (2013). Conceptual challenges for understanding the equivalence of expressions - a case study. In B. Ubuz, Ç. Haser, \& M.A. Mariotti (Eds), Proceedings of the eighth congress of European research in mathematics education (CERME 8) (pp.558-567). Antalya, Turkey: ERME.

\section{http://www.ejmste.com}

